\title{
Effect of the luxI/R gene on AHL-signaling molecules and QS regulatory mechanism in Hafnia alvei $\mathrm{H} 4$
}

Xue Li ${ }^{1,2}$ (-), Gongliang Zhang ${ }^{1,2}$, Yaolei Zhu ${ }^{1,2}$, Jingran $\mathrm{Bi}^{1,2}$, Hongshun $\mathrm{HaO}^{2}$ and Hongman $\mathrm{Hou}^{1,2^{*}}$

\begin{abstract}
Hafnia alvei $\mathrm{H} 4$ is a bacterium subject to regulation by a $\mathrm{N}$-acyl-I-homoserine lactone (AHL)-mediated quorum sensing system and is closely related to the corruption of instant sea cucumber. Studying the effect of Hafnia alvei $\mathrm{H} 4$ quorum sensing regulatory genes on AHLs is necessary for the quality and preservation of instant sea cucumber. In this study, the draft genome of $\mathrm{H}$. alvei $\mathrm{H} 4$, which comprises a single chromosome of 4,687,151 bp, was sequenced and analyzed and the types of AHLs were analyzed employing thin-layer chromatography (TLC) and high resolution triple quadrupole liquid chromatography/mass spectrometry (LC/MS). Then the wild-type strain of $\mathrm{H}$. alvei $\mathrm{H} 4$ and the luxl/R double mutant $(\triangle /$ uxIR) were compared by transcriptome sequencing (RNA-seq). The results indicate that the incomplete genome sequence revealed the presence of one quorum-sensing (QS) gene set, designated as las//expR. Three major AHLS, N-hexanoyl-L-homoserine lactone (C6-HSL), N-butyryl-L-homoserine lactone (C4-HSL), and N-(3-oxo-octanoyl)L-homoserine lactone (3-oxo-C8-HSL) were found, with C6-HSL being the most abundant. C6-HSL was not detected in the culture of the lux/ mutant ( $\triangle / u x I)$ and higher levels of C4-HSL was found in the culture of the luxR mutant ( $\triangle / u x R)$, which suggested that the luxR gene may have a positive effect on C4-HSL production. It was also found that AHL and QS genes are closely related in the absence of luxIR double deletion. The results of this study can further elucidate at the genetic level that luxl and luxR genes are involved in the regulation of $\mathrm{AHL}$.
\end{abstract}

Keywords: AHLs, luxl/luxR, Hafnia alvei, Genome, Transcriptome

\section{Introduction}

It is widely accepted that bacteria (both planktonic and biofilm cells) communicate with each other by sensing and releasing signaling compounds in a process commonly known as quorum sensing (QS) (Miller and Bassler 2000). This process is composed of an $N$-acyl-1-homoserine lactone (AHL) synthase (a LuxI-type family protein) and an AHL reporter (a LuxR-type family transcription regulator) (Kumar et al. 2016). LuxI family proteins are AHL synthases that catalyze the acylation of $S$-adenosylmethionine (SAM) via an acyl carrier protein (acyl-ACP) or CoA-aryl/acyl moieties to produce AHLs (Parsek et al. 1999; Dong et al. 2017). In this reaction, SAM supplies

\footnotetext{
*Correspondence: houhongman@dlpu.edu.cn

${ }^{1}$ School of Food Science and Technology, Dalian Polytechnic University, No.1, Qinggongyuan, Ganjingzi District, Dalian 116034, China Full list of author information is available at the end of the article
}

the amino group and acyl-ACP provides the acyl group. These molecules are used by Gram-negative bacteria as common signaling molecules and are involved in the regulation of biofilm formation and other properties of the bacteria (Galloway et al. 2012; Guo et al. 2017). When the concentration of an AHL reaches a threshold as a result of an increase in bacterial cell density, members of the LuxR protein family, which consist of the AHL receptors, would bind to the AHL to regulate the expression of numerous genes involved in various processes, including bioluminescence, pigment and/or antibiotic production, and virulence (Waters and Bassler 2005). So far, more than 37 genera of gram-negative bacteria have been identified that are regulated by AHL signaling molecules (Kimura 2014).

Hafnia alvei is a Gram-negative, facultatively anaerobic, rod-shaped and motile bacterium of the Enterobacteriaceae family. It is also an opportunistic pathogen and a 
dominant psychrophile found in putrid food (Vivas et al. 2008). Hafnia alvei is also commonly found in abundance among the communities of the $\mathrm{N}$-acylhomoserine lactone (AHL)-producing food spoilers (Bruhn et al. 2004; Pinto et al. 2007). In addition, $H$. alvei is considered to be the most common biological contaminant in vacuumpacked frozen meat (Bruhn et al. 2004). This bacterium is known to produce $\mathrm{N}$-(3-oxohexanoyl) homoserine lactone (3-oxo-C6-HSL) (Viana et al. 2009). Although $H$. alvei plays an important role either in the decay of meat or other vacuum-packed foods, little research has been carried out to determine the specific interaction mechanisms between AHLs and luxI/luxR genes in the H. alvei community.

In this study, we first studied the relationship between the $l u x I / R$ gene and different AHLs produced by $H$. alvei $\mathrm{H} 4$, first by using TLC and LC/MS, and then by sequencing the draft genome of $H$. alvei $\mathrm{H} 4$ to characterize its QS system at the molecular level. Further, RNA-seq-based transcriptome analysis was employed to obtain important insights into the gene expression patterns and regulatory elements of $H$. alvei (Sorek and Cossart 2010). To our knowledge, this has been the first transcriptomewide study conducted on $H$. alvei to shed further light on the molecular mechanism of AHL-mediated QS.

\section{Materials and methods}

\section{Bacterial strains and culture conditions}

The bacterial strains used in this study were wild-type $H$. alvei (the strain number is CCTCC AB 2019337 Hafnia alvei $\mathrm{H} 4)$ and three mutants, one lacking the luxI gene $(\Delta l u x I)$, one lacking the $l u x R$ gene $(\Delta l u x R)$, and another one lacking both $l u x I$ and $l u x R$ genes $(\Delta l u x I R)$. All the mutants mentioned above were constructed by the laboratory before (Hou et al. 2019). In addition, the mini-Tn5 mutant of Chromobacterium violaceum (CV026) was also used. Wild-type $H$. alvei $\mathrm{H} 4$ was previously isolated in our laboratory and from instant sea cucumber. The mutants were also constructed in our laboratory. All bacterial strains were stored at $-80{ }^{\circ} \mathrm{C}$. CV026 was provided by the Chinese Academy of Agricultural Sciences (Gelencsér et al. 2012a, b). They were routinely cultured in Luria-Bertani (LB) broth (10 g tryptone per liter, $5 \mathrm{~g}$ yeast extract, $5 \mathrm{~g} \mathrm{NaCl}$ per liter) with $\mathrm{pH}$ adjustment of 7. Except where indicated, bacteria were grown at $30{ }^{\circ} \mathrm{C}$ with shaking at $150 \mathrm{rpm}$.

\section{AHL extraction and characterization}

AHLs were extracted from the supernatants of different bacterial culturesas previously described (Ravn et al. 2001). The extracted AHLs were first identified by TLC as described by Hou et al. (2018), but with some modification. In brief, a reverse phase C18 TLC plate (Merck,
Darmstadt, Germany) was cut into $10 \times 7.5 \mathrm{~cm}$ strips, and the extracted AHLs and standard AHLs [C4-HSL $(800 \mu \mathrm{g} / \mathrm{mL}), \mathrm{C} 6-\mathrm{HSL}(50 \mu \mathrm{g} / \mathrm{mL})$ and $3-\mathrm{O}-\mathrm{C} 8-\mathrm{HSL}$ $(0.5 \mathrm{mg} / \mathrm{mL})]$ obtained from Sigma-Aldrich (St. Louis, MI, USA) were spotted onto one end of the strip about $1 \mathrm{~cm}$ from the edge of the strip, and with a spacing of $1 \mathrm{~cm}$ between spots. The spots were allowed to dry and the strip was developed in methanol/water $(60 \% / 40 \%$, $\mathrm{v} / \mathrm{v})$. After development, they were air-dried in a $30{ }^{\circ} \mathrm{C}$ incubator, and the dried strip was then put into a culture dish and overlaid with a thin layer of LB top agar containing CV026, using a 1:2 volume ratio of CV026 suspension to LB agar medium. After setting, the plate was incubated at $30{ }^{\circ} \mathrm{C}$ for overnight. The presence of AHL would result in the appearance of purple spots in the agar, indicative of AHL-induced production of violacein (Chen et al. 2013; Okutsu et al. 2015).

The concentration of the major AHLs extracted from the bacterial culture supernatants were then quantified by LC/MS, with reference to a standard curve constructed for each of the three standards (C4-HSL, C6-HSL and 3-O-C8-HSL).

The conditions used for LC/MS are shown in Table 1. The setting of each parameter was adapted from the method of Hou et al. (2017) with slight modification. Elution of the samples was achieved by a gradient consisting of solvent A (water) and solvent B (acetonitrile). The gradient commenced with $90 \%$ A for 2 min and rising to $95 \% \mathrm{~A}$ in $1 \mathrm{~min}$, and then remained at $95 \% \mathrm{~A}$ for $2 \mathrm{~min}$. This was followed by a rapid decrease to $85 \% \mathrm{~A}$ in $1 \mathrm{~min}$ and remained at $85 \% \mathrm{~A}$ for $9 \mathrm{~min}$. After that, the gradient was further dropped to $70 \% \mathrm{~A}$ in $5 \mathrm{~min}$, and then to $50 \% \mathrm{~A}$ in $5 \mathrm{~min}$.

\section{Table 1 LC and MS conditions used in AHL detection}

\begin{tabular}{lll}
\hline LC condition & LC condition & $\varphi 4.6 \times 150 \mathrm{~mm}, 5 \mu \mathrm{m}$ (Agilent) \\
& Column temperature & $30{ }^{\circ} \mathrm{C}$ \\
& Inject volume & $6 \mu \mathrm{L}$ \\
& Mobile phase & Water/acetonitrile \\
& Flow rate & $1.0 \mathrm{~mL} / \mathrm{min}$ \\
& Measurement time & $35 \mathrm{~min}$ \\
MS condition & MS & $5500 \mathrm{AB}$ SCIEX \\
& Ionization mode & $\mathrm{ESI+}$ \\
& Ion source & Turbo spray \\
Curtain gas (CUR) & $20 \mathrm{psi}$ \\
Ionspray voltage (IS) & $5000 \mathrm{~V}$ \\
Temperature (TEM) & $450{ }^{\circ} \mathrm{C}$ \\
Ion source gas1 (GS1) & $30 \mathrm{psi}$ \\
Ion source gas2 (GS2) & $10 \mathrm{psi}$ \\
Collision gas (CAD) & Medium
\end{tabular}

$A H L$ acyl homoserine lactone, $L C-M S$ liquid chromatography-tandem mass spectrometry 
For the MS/MS system, optimum quantitative ion pairs $(\mathrm{m} / \mathrm{z})$ were determined under Multiple Reaction Monitoring (MRM) mode. The MRM parameters are shown in Table 2.

\section{Genome sequencing of wild type $\mathrm{H}$. alvei $\mathrm{H} 4$}

Total DNA of $H$. alvei $\mathrm{H} 4$ was extracted from the cell pellet using a Wizard ${ }^{\circledR}$ Genomic DNA Purification Kit (Promega, USA). The purity, concentration and integrity of the DNA sample were then tested. Specifically, the purity of the DNA preparation was measured by NanoDrop2000 (Thermo, USA). DNA concentration was measured by picogreen (QuantiFluor ${ }^{\circledR}$ dsDNA System E2670, Promega, USA), and DNA integrity was determined by $1 \%$ agarose gel electrophoresis (LONZA, Switzerland). For quality tested samples, DNA fragments of the required length were recovered, and then a linker for cluster preparation was added. Finally, the whole genome re-sequencing was completed by the Illumina Hiseq 4000 sequencing technology (Hiseq $\mathrm{X}$ Ten Reagent Kit v2.5, Illumina, USA) and an Illumina PE library (450 bp) was constructed. The bioinformatics part mainly usedthe BWA software (http://bio-bwa.sourceforge.net/) to compare the obtained reads with the reference genome sequence. The SNP (single nucleotide polymorphism) and small indel information was detected by VarScan software (http://varscan.sourceforge.net/), and the sites with lower sequencing depth and lower quality values were filtered out. Then the annotation information of SNP and indel was obtained using the Annovar software (http://annovar.openbioinformatics.org/en/latest/) and the gff information of the reference genomes, Hafnia alvei strain HUMV-5920 (https://www.ncbi.nlm.nih.gov/ pubmed/27313299) and Hafnia alvei FB1 (https://www. ncbi.nlm.nih.gov/genome/?term $=$ Hafnia+alvei+) for annotation. Finally, the gene family enrichment analysis of SNP-related genes was performed based on the interpro annotation information of the SNP-corresponding genes.

\section{Preparation of $\mathrm{H}$. alvei $\mathrm{H} 4$ transcriptome samples}

RNA samples were harvested from wild-type $H$. alvei $\mathrm{H} 4$ and its mutant $\Delta l u x I R$. The samples were designated as W12-1, W12-2, W12-3 for wild type and IR-1, IR-2, IR-3 for $\Delta l u x I R$. In brief, $100 \mathrm{~mL}$ LB medium was inoculated with freshly grown preculture of the wild type or $\Delta l u x I R$ and then cultured for $12 \mathrm{~h}$ at $30{ }^{\circ} \mathrm{C}$ with shaking at $150 \mathrm{rpm}$. After $12 \mathrm{~h}$, the cultures were dispensed into $50-\mathrm{mL}$ centrifuge tubes, chilled on ice, and centrifuged at $8000 \times g$ for $10 \mathrm{~min}$. The supernatant was discarded, and the cell pellet was directly frozen in liquid nitrogen and stored at $-80{ }^{\circ} \mathrm{C}$ until further use. A total of six independent biological samples were analyzed by RNA-seq analysis, representing three replicates for each of the two strains.

\section{RNA extraction and quality verification}

RNA-seq libraries for wild-type $H$. alvei $\mathrm{H} 4$ and $\Delta l u x I R$ were constructed from each three different preparations of RNA. Total RNA was extracted from the cells using an RNAprep pure Cell/Bacteria Kit (Tiangen biotech, Beijing, China) according to the manufacturer's instructions. RNA degradation and contamination were monitored by electrophoresis using $1 \%$ agarose gel (Bio-Rad, CA, USA). The purity, concentration and integrity of the DNA sample were then tested. Specifically, the purity of the RNA was checked by spectrophotometry using a NanoPhotometer ${ }^{\circledR}$ spectrophotometer (IMPLEN, CA, USA). The concentration of RNA was measured with a Qubit $^{\circledR}$ RNA Assay Kit in Qubit ${ }^{\circledR}$ 2.0 Fluorometer (Life Technologies, CA, USA), whereas the integrity of the RNA was determined using an RNA Nano 6000 Assay Kit of the Bioanalyzer 2100 system (Agilent Technologies, CA, USA).

\section{Library construction and sequencing}

A total amount of $3 \mu \mathrm{g}$ RNA per sample was used as input material for the six qualified RNA samples. Sequencing libraries were generated using NEBNext ${ }^{\circledR}$ Ultra $^{\mathrm{TM}}$ Directional RNA Library Prep Kit for Illumina ${ }^{\circledR}$ (NEB, USA) according to the manufacturer's recommendations, and index codes were added to attribute sequences to each sample. Briefly, mRNA was purified from the total RNA using poly-T oligo-attached magnetic beads. For prokaryotic samples, rRNA was removed using a specialized kit. In order to select cDNA fragments of 150$200 \mathrm{bp}$ in length, the library fragments were purified with AMPure XP system (Beckman Coulter, Beverly, USA), and $3 \mu \mathrm{L}$ USER Enzyme (NEB, USA) was then used with size-selected and adaptor-ligated cDNA at $37{ }^{\circ} \mathrm{C}$ for

Table 2 Selected product ion $\mathrm{m} / \mathrm{z}$ values and MRM parameters used for AHL analysis

\begin{tabular}{lllllllr}
\hline Signals & Molecular formula & Q1/Q3 & DP (V) & EP (V) & CE (V) & CXP (V) & Retention time \\
\hline C4-HSL & $\mathrm{C}_{8} \mathrm{H}_{13} \mathrm{NO}_{3}$ & $172.1 / 102.1$ & 90.0 & 10.0 & 15.0 & 13.0 & 5.01 \\
C6-HSL & $\mathrm{C}_{10} \mathrm{H}_{17} \mathrm{NO}_{3}$ & $200.1 / 102.1$ & 90.0 & 10.0 & 15.0 & 13.0 & 19.9 \\
3-O-C8-HSL & $\mathrm{C}_{12} \mathrm{H}_{19} \mathrm{NO}_{4}$ & $242.1 / 102.1$ & 90.0 & 10.0 & 15.0 & 13.0 & 23.2 \\
\hline
\end{tabular}


15 min followed by $5 \mathrm{~min}$ at $95^{\circ} \mathrm{C}$ before PCR. PCR was performed with Phusion HighFidelity DNA polymerase (NEB, USA), Universal PCR primers and Index (X) Primer. At last, all samples were purified (AMPure XP system) and the quality of the library was assessed by the Agilent Bioanalyzer 2100 system (Agilent Technologies, CA, USA).

\section{Data analysis}

Clean reads were obtained by removing reads containing adapter, reads containing ploy- $\mathrm{N}$ and low-quality reads from raw data. Both the building index of the reference genome and the alignment of clean reads to the reference genome were performed using Bowtie2-2.2.3. Differential expression analysis of the IR12-W12 experimental group was performed using the DESeq R package (1.18.0) (Love et al. 2014) and DEseq was used to estimate the variancemean dependence in count data from high-throughput sequencing assays and test for differential expression based on a model using the negative binomial distribution (Langmead and Salzberg 2012). The resulting P-values were adjusted using the Benjamini and Hochberg's approach for controlling the false discovery rate. Genes with an adjusted $P$-value $<0.05$ found by DESeq were assigned as differentially expressed (Anders and Huber 2010). All data were analyzed on the online platform of Novomagic Cloud Platform (https://magic.novogene. com/public/customer/login).

\section{Accession number(s)}

The incomplete draft genome sequence of the $H$. alvei $\mathrm{H} 4$ has been uploaded to the National Center for Biotechnology Information (NCBI) database under the accession number SDAR00000000. Raw and processed transcriptome data have been deposited at the Gene Expression Omnibus (GEO) database under the accession number GSE137815.

\section{Results}

\section{Secretion of AHLs by $\mathrm{H}$. alvei $\mathrm{H} 4$ wild type and mutants}

In order to comprehensively analyze the AHLs produced by the QS system of $H$. alvei H4, the AHLs extracted from the cultures of wild type and three mutants $(\Delta l u x I$, $\Delta l u x R$ and $\Delta l u x I R)$ at different time points were first subjected to TLC analysis.

In the presence of the biosensor mini-Tn 5 mutant of C. violaceum (CV026), the AHL extracts from wild type and $\Delta l u x R$ consistently produced two purple spots on the TLC plate, which corresponded to the two short-chain AHL standards, C4-HSL and C6-HSL (Fig. 1), whereas the extracts from $\Delta l u x I$ and $\Delta l u x I R$ did not produce any detectable AHL (data not shown) (Khajanchi et al. 2009). In the cases of wild type, changes in the production of C4-HSL and C6-HSL were followed by a similar pattern, and neither could be detected at zero time because the cell density was too low. Six hours after incubation, the two AHLs became detectable and their levels reached a peaked at $24 \mathrm{~h}$ and remained detectable even at $30 \mathrm{~h}$, but no purple spot was detected at $36 \mathrm{~h}$. Production of C4-HSL and C6-HSL were slightly different
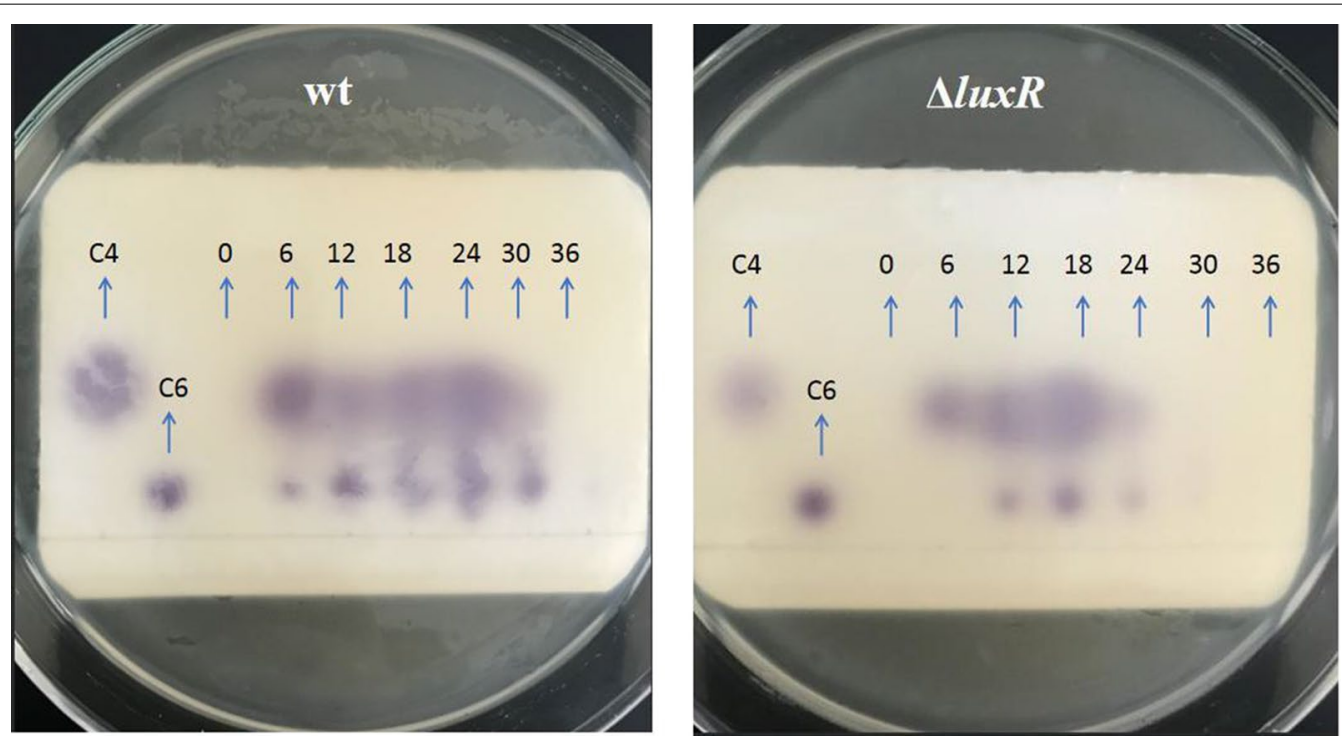

Fig. 1 TLC bioassay of AHLs produced by H. alvei H4 wt and $\triangle l$ uxR with C. violaceum CV026 as a sensor strain. Lane 1: C4-HSL standard AHL; Lane 2: C6-HSL standard AHL; Lane 3-Lane 9: 0-36 h every $6 \mathrm{~h}$ of AHL extracted from H. alvei H4 wild type and mutant strain culture supernatant 
in $\Delta l u x R$, whereby no AHL was detected at $0 \mathrm{~h}$. At $6 \mathrm{~h}$, only C4-HSL was detected, and its level remained detectable until $24 \mathrm{~h}$. For the C6-HSL, it was only detected at $12 \mathrm{~h}$ and no obvious purple halo could be seen after $24 \mathrm{~h}$. Maximum levels of the two AHLs produced by $\Delta l u x R$ occurred at $18 \mathrm{~h}$, somewhat earlier compared with the wild type. Moreover, the maximum AHL level in the wild type and $\triangle l u x R$ cultures corresponded to the maximum cell density $\left(\mathrm{OD}_{600}\right.$ of 2.0 for wild type and 1.8 for $\left.\Delta l u x R\right)$.

The levels of AHLs produced by both wild type and $\triangle l u x R$ were quantified by LC/MS. The result revealed the presence of three AHLs, C4-HSL, C6-HSL and 3-O-C8-HSL, with the first two present in much higher levels, peaking at $24 \mathrm{~h}$ in the case of wild type and at $18 \mathrm{~h}$ for $\Delta l u x R$ (Fig. 2), consistent with the result obtained by TLC. Furthermore, in the case of $\triangle l u x R$, the concentration of C6-HSL did not change significantly over time, whereas the concentration of C4-HSL increased with incubation time. As for 3-O-C8-HSL, its concentration was extremely low, so no significant change was detected over time. Production of AHL by $\Delta l u x I$ and $\Delta l u x I R$ was quite different from wild type and $\Delta l u x R$. Not all the three AHLs produced by wildtype and $\Delta l u x R$ were detected in the cultures of $\Delta l u x I$ and $\Delta l u x I R$. For example, C6-HSL was completely undetectable in both $\Delta l u x I$ and $\Delta l u x I R$ cultures, and C4-HSL production in the $\Delta l u x I$ culture was reduced but was not detected in $\Delta l u x I R$ culture, whereas the production of 3-O-C8-HSL was significantly reduced in both cultures (Fig. 2). The result showed that at least, three distinct AHLs were produced by $H$. alvei $\mathrm{H} 4$, with C4-HSL being the main one, while 3-O-C8-HSL and C6-HSL being the minor AHLs. Furthermore, the result also demonstrated the importance of the luxI gene in the synthesis of C6-HSL and 3-O-C8-HSL, and suggested that the synthesis of C4-HSL might not depend on the luxI gene.

In order to understand the molecular mechanisms of luxI/luxR gene and AHLs and further exploit its potentials, the genome of $H$. alvei $\mathrm{H} 4$ was sequenced and analyzed. The sequencing data revealed a high GC content (48.75\%) in the genome of $H$. alvei $\mathrm{H} 4$, and 66 scaffolds were detected with a total genome length of 4,687,151 bp. To determine whether $H$. alvei $\mathrm{H} 4$ might contain an additional quorum sensing systems, its genome was searched for the presence of luxI and luxR homologous genes, and one luxI-type acyl-homoserine-lactone synthase gene (termed lasI, gene0750) and two luxR-type (termed $\exp R$, gene0751; luxR (unnamed), gene2065) transcriptional regulators were identified (Fig. 3). $\exp R$ contained 19 bases overlapping with lasI and was located downstream of lasI, both of which were located in the second scaffold. In addition, another orphan luxR-type transcriptional regulator gene [solo $\mathrm{R}$ gene (Subramoni and Venturi 2009)] was found on the fourth scaffold without an adjacent luxI gene (Fig. 3). All these data were analyzed on the free online platform of Majorbio I-Sanger Cloud Platform (http://www.i-sanger.com). Additionally, due to the variability of gene names, luxI/R would still be used instead of the new annotated lasI/expR, which

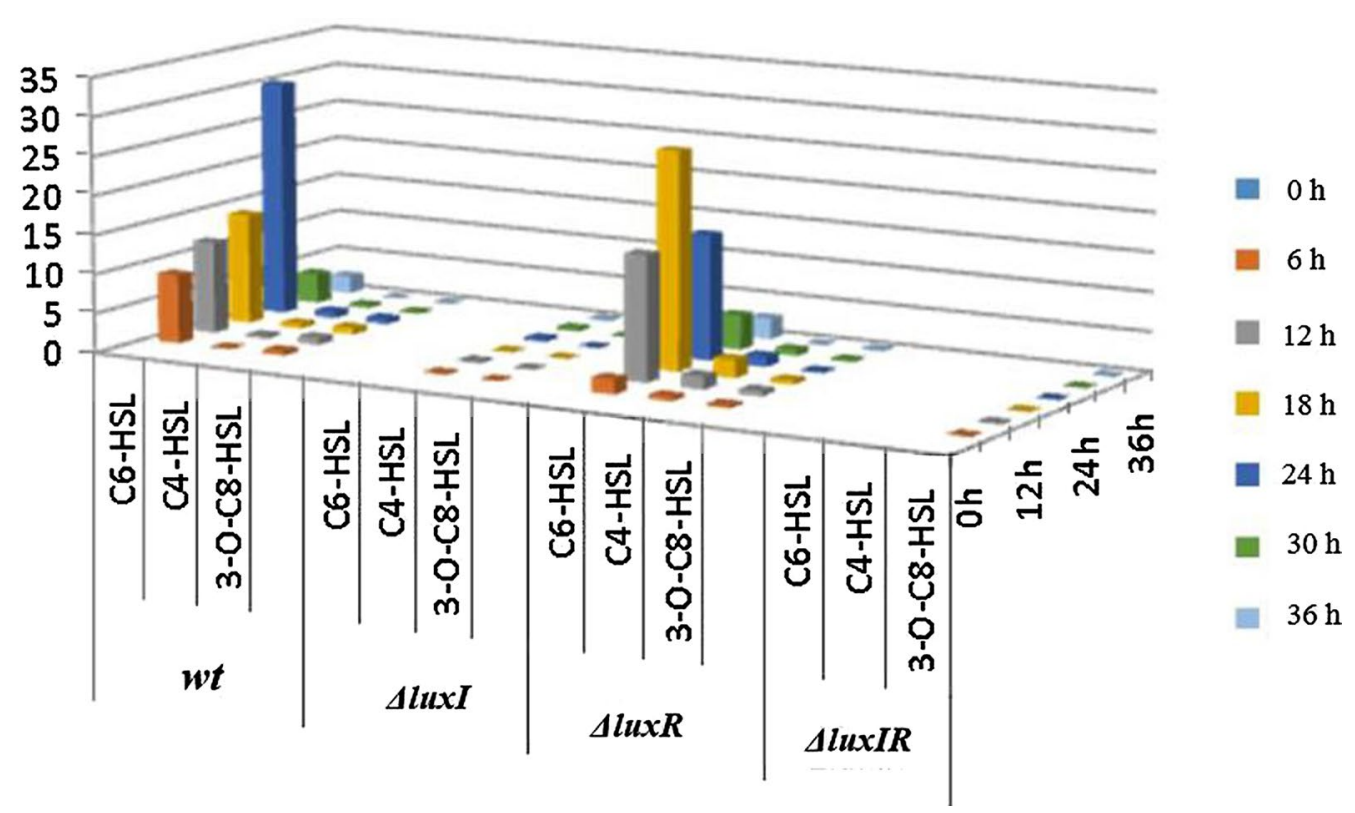

Fig. 2 The AHL extracts of wild-type H. alvei $H 4$ and its $\triangle / u x l, \Delta / u x R, \Delta l u x I R$ mutants at different times were detected by LC/MS 


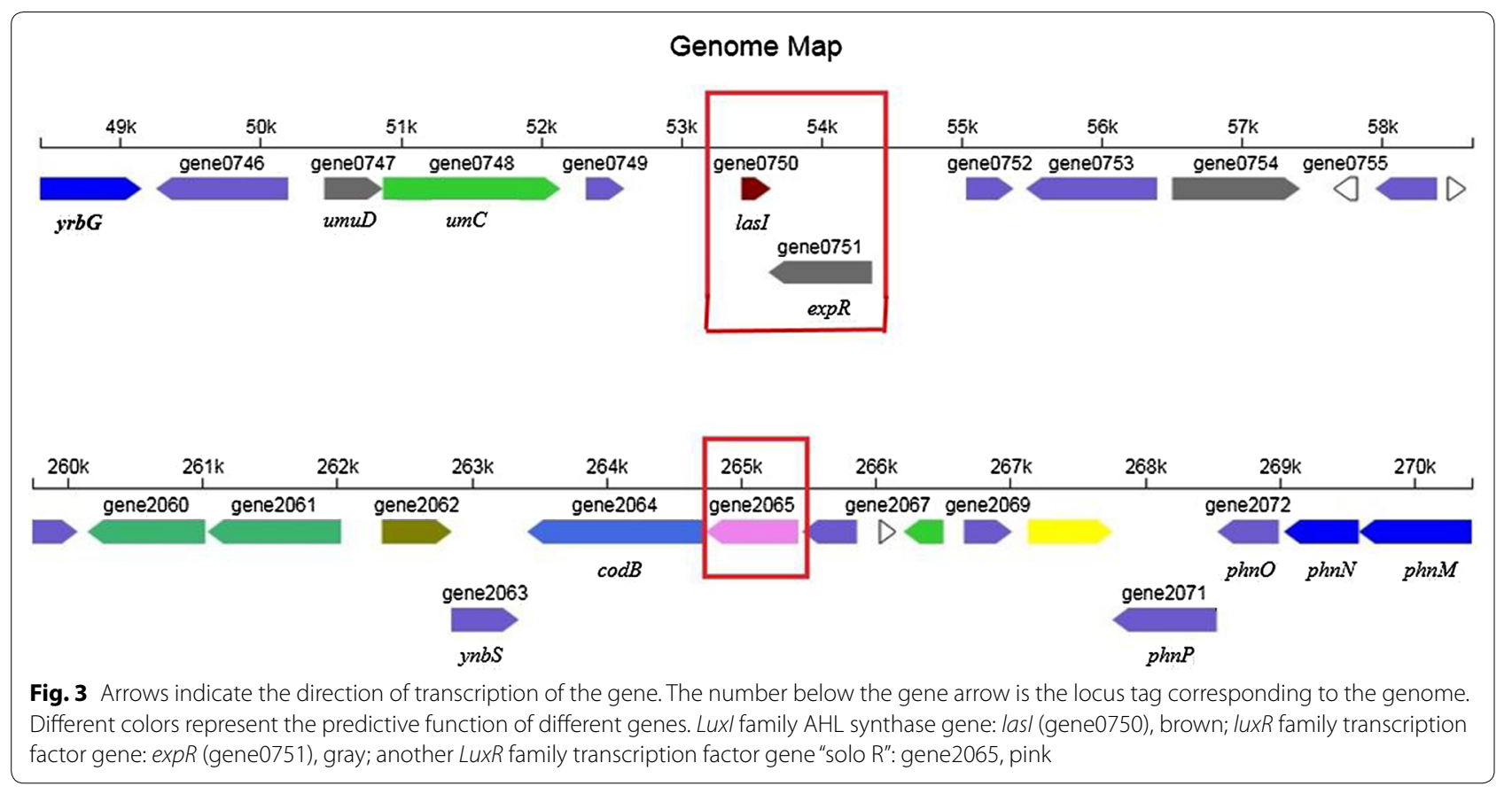

is consistent with the name previously used for this gene (Hou et al. 2017, 2018).

\section{Transcriptome analysis of AHL-related QS genes in $H$. alvei H4 wt and $\Delta /$ uxIR}

In order to elucidate the expression patterns of the $l u x I / R$ gene, transcriptome profiling was performed via RNAsequencing (RNA-seq). Three independent biological replicates per strain were processed and sequenced. Read counts obtained for each sample were FPKM (fragments per kilobase of exon per million fragments mapped) normalized prior to being analyzed for differentially expressed genes. Subsequently, transcript reads were mapped to the $H$. alvei $\mathrm{H} 4$ genome. The mapped reads were filtered based on the mapping quality and only uniquely mapped reads were used for further analysis (Table 3). An extremely high correlation between each independent replicate and its respective counterpart be used, which indicated high reproducibility. Moreover, to investigate the changes in $H$. alvei $\mathrm{H} 4$ gene expression patterns following the knockout of the luxIR genes, the differentially expressed genes (DEGs) were aligned with the KEGG pathways to elucidate the biological functions of the DEGs. All DEGs were matched to 90 KEGG pathways (some genes could be simultaneously enriched into multiple pathways). The pathways that we focused on was not the most significantly enriched Bacterial chemotaxis (KEGG: ko02030) or other metabolic pathways, but QS pathway (KEGG: ko02024), and 5 down-regulated genes and 12 up-regulated genes were found to associate with this pathway.

\section{Discussion}

In this study, three AHLs were quantified by TLC and $\mathrm{LC} / \mathrm{MS}$ in order to investigate their secretion patterns and their relationship with the $l u x I$ and $l u x R$ genes. Firstly, stimulation or inhibition of violacein production by the AHL-dependent biosensor CV026 could be used in the TLC overlay to roughly detect the different AHL molecules that are structurally diverse (McClean et al. 1997). The sensitivity of CV026 to AHLs has enabled the different AHLs synthesized by H. alvei $\mathrm{H} 4$ to

Table 3 Statistics of reads that mapped to Hafnia alvei $\mathbf{H} 4$ genome per sample analysed

\begin{tabular}{lccccc}
\hline Sample & W12-1 & W12-2 & W12-3 & IR-1 & IR-2 \\
\hline Total mapped reads (\%) & 98.73 & 98.7 & 98.88 & 98.8 & 98.81 \\
Uniquely mapped reads (\%) & 97.81 & 97.84 & 98.02 & 97.95 \\
RNA integrity number (RIN) & 9.9 & 8.1 & 9.8 & 9.4 \\
\hline
\end{tabular}

Samples W12-1, W12-2, W12-3 and IR-1, IR-2 and IR-3 represent biological replicates for RNA isolated from the $\mathrm{H}_{4}$ mutant at OD $600=1.7$

$O D$ optical density, IR LuxIR gene mutant, $W$ wild-type 
be separated and identified by TLC. The two shortchain AHLs (C4-HSL and C6-HSL) and one mediumchain AHL (3-O-C8-HSL) can stimulate the production of violacein by $C$. violaceum CV026 (Frederix and Downie 2011) and therefore, we concluded that AHLs were produced by the two tested $H$. alvei $\mathrm{H} 4$ strains (wild type and $\Delta l u x R$ ) because CV026 can only produce violacein in the presence of an exogenous supply of AHLs (AKabir et al. 2010). No obvious purple halo in response to the 3-O-C8-HSL standard was observed in the TLC result since CV026 is not sensitive to the 3-O-C8-HSL, and the level of 3-O-C8-HSL produced by $H$. alvei $\mathrm{H} 4$ may be low, and so $H$. alvei $\mathrm{H} 4$ could only weakly induce CV026 to produce violecein (data not shown).

AHL tends to accumulate when the cell density increases and once the concentration of AHL reaches a certain threshold, the whole bacterial population responds homogeneously upon the specific activation of target genes (Camilli and Bassler 2006). Therefore, it is not difficult to understand that at $0 \mathrm{~h}$, no visible purple halo was observed because the number of bacterial cells in the culture was too low. Furthermore, due to the difference in color rendering properties of the different AHLs, the color reaction produced by CV026 showed a different purple halo size. The purple halo corresponding to C4-HSL observed in the TLC plate was relatively larger, but the LC/MS results did not indicate that abundant C4-HSL was synthesized by wild-type $H$. alvei $\mathrm{H} 4$. Among the three AHLs examined, C6-HSL was present in the lowest level, but it produced the largest spot in the TLC plate and also yielded the highest peak in the LC/ MS spectrum. Therefore, the most abundant AHL produced by $H$. alvei $\mathrm{H} 4$ was C6-HSL. In addition, none of the three AHLs were detected in the $\Delta l u x I$ and $\Delta l u x I R$ cultures via TLC, which might be due to an inability to synthesize AHLs and hence, an impaired QS-regulated violacein production or the concentration of the AHL synthesized was too low to be detected, confirming that luxI could be the signaling synthase (Coutinho et al. 2013; Patzelt et al. 2013). Furthermore, these three AHLs were either not detected or detected in very low levels by LC/MS in the case of $\Delta l u x I$, suggesting that the luxI gene might control the synthesis of AHLs, and it was not surprising that AHLs could still be detected in the $\Delta l u x R$ culture. Similarly, in A. hydrophila, mutation in the ahyR gene did not result in the loss of C4-HSL synthesis, and C4-HSL was present in the stationary phase of both the parent and ahyR mutant (Swift et al. 1999). Overall, we could initially conclude that the acyl homoserine lactone enzyme luxI in $H$. alvei $\mathrm{H} 4$ is important for the synthesis of AHLs, and that the receptor regulatory protein LuxR seems to be essential in this process.
To date, only three other $H$. alvei genomes have been sequenced, one is from strain ATCC 51873, isolated from the gut; another is BIDMC 31, which was investigated as part of the carbapenem resistance study, and was isolated from unspecified clinical source (http://www.ncbi. nlm.nih.gov/genome) (Tan et al. 2014). The third genome sequencing was performed for $H$. alvei FB1 isolated from fish meatballs, also a marine source, similar to $H$. alvei $\mathrm{H} 4$, which was isolated from instant sea cucumbers. Therefore, the strains that have been sequenced have certain reference significance for follow-up analysis. In this study, the genome of $\mathrm{H}$. alvei $\mathrm{H} 4$ was sequenced and the positional relationship of QS-related genes was found throughout the genome data set. Firstly, in the $H$. alvei $\mathrm{H} 4$ genome, luxI and luxR were found to have opposite orientation and 19 base overlaps, with the same positional overlap as a pair of QS genes in H. alvei FB1 (Tan et al. 2014), whereas in $H$. alvei FB1, luxI is located downstream of $\operatorname{luxR}$. Another similarity is that only one luxItype gene was found in the $H$. alvei FB1 genome, except that it has six $\operatorname{luxR}$ genes, including a gene overlapping the luxI gene and five independent luxR genes. Studies have reported that conserved gene overlaps are another commonality observed in short, conserved topologies. Within the class of simple topologies, the majority of the cases are made up of the $\vec{R} \vec{I}$ and $\vec{R} \overleftrightarrow{I}$ the topologies that Goryachev termed type A and type B (Gelencsér et al. 2012a, b; Goryachev 2009, 2011). As for H. alvei H4, the positional relationship in the genome was found to belong to the second type of topology (Fig. 3). Such overlap is not uncommon in gene circuits where bacteria are tightly co-regulated (Krakauer 2000), such as restrictive modification systems (Kaw and Blumenthal 2010). The L1 type QS circuit of $P$. aeruginosa contains an overlap of $10 \mathrm{bp}$ and the same overlap is $20 \mathrm{bp}$ long in P. fuscovaginae. In contrast, $P$. putida has an L1 circuit where the $\mathrm{R}$ and $\mathrm{L}$ circuits are close (4 bp apart) but not overlapping (Gelencsér et al. 2012a, b). Other examples of the luxR gene have also been identified in locations that are separated from the QS circuit lacking the homologous $\mathrm{N}$-AHL synthase, this luxR gene is referred to as solo (Hou et al. 2017) or orphan (Lequette et al. 2006) and is believed to allow the bacteria to perceive environmental stimuli and/or AHL produced by neighboring bacteria in that these $\operatorname{luxR}$ solos, which perceive environmental stimuli, contain the AHL-binding domain at the $\mathrm{N}$ terminus and a DNA-binding helix-turn-helix (HTH) domain at the C-terminus (Case et al. 2008; Cude and Buchan 2013; Fuqua 2006; González and Vittorio 2013; Tsai and Winans 2010). The specific function of most of these is currently unknown, however, among those $\operatorname{luxR}$ solos that have been studied up to now, many are interconnected with the resident AHL-QS systems. Or 
as previously found, the most striking feature of various circuit topologies is the potential negative regulation of luxI-type gene by luxR-type gene, in parallel with the well-known positive regulation. In other words, in many cases, $l u x R$ can both activate and suppress the luxI gene (Lequette et al. 2006). The phenomenon in the TLC experiment indicated a higher concentration of C4-HSL in the $\Delta l u x R$ mutant compared with wt (Fig. 1), which is contrary to the secretion rule of C6-HSL. We suspected that this may be a negative regulation of luxI gene by $\operatorname{luxR}$ gene in the overlapping gene pair, resulting in the high expression of C4-HSL, a regulatory pattern parallel to the positive regulatory mode of C6-HSL. In the $\Delta l u x R$, the $l u x R$ gene with the overlapping fragment of the $l u x I$ gene was disrupted, and the inhibitory effect of luxR on $l u x I$ disappeared, thereby negatively regulating the expression of the $l u x I$ gene and expressing more C4-HSL. As gene overlaps and $l u x R$ solos have been reported in other bacteria, their existence in $H$. alvei $\mathrm{H} 4$ genome was not surprising. The different secretion patterns of C4-HSL, C6-HSL and 3-O-C8-HSL in wt, $\Delta l u x I, \Delta l u x R$, $\triangle l u x I R$ suggested that the LuxR protein regulated AHL expression either positively or negatively.

Although the genome is considered to be the blueprint for life, much information about the physiological or metabolic processes cannot be obtained directly from the genome (Wiegand et al. 2013). To this end, RNA-seqbased transcriptomics analysis was employed to provide a simpler and more efficient method (Nagalakshmi et al. 2010). For the selection of the subjects, we referred to the mbaI/R-type QS regulation model of methane-oxidizing bacteria. In methane-oxidizing bacteria, the addition of AHL extract to a strain containing the Pmbal-gfp plasmid, but not the mbaR-expressing plasmid, did not result in an increase in GFP fluorescence (Weeks et al. 2010). This process is, therefore, MbaR dependent and MbaR activates the expression of the synthase gene mbal, upon signal binding, in a possible positive feedback loop. The combined results of TLC and LC/MS analysis in this study showed that the luxR gene may also act on the luxI gene, affecting the expression of C4-HSL. Therefore, in order to obtain more convincing evidence, we selected the luxIR double deletion strain and wild type to form a control group to further explore the changes in the transcription level of AHLs synthesis-related genes. The RNA sequencing results showed that $>800$ genes were differentially expressed in $H$. alvei $\mathrm{H} 4$ when both luxI and luxR were deleted. These results indicated that $l u x I / R$ QS could have an immense influence on gene expression in $H$. alvei $\mathrm{H} 4$. For this section, based on the established DEGs and related KEGG pathways analyses, we focused on the QS response of genes controlling AHL synthesis in $H$. alvei $\mathrm{H} 4$ at the transcriptome level. Seventeen genes out of 59 genes fell into QS and RNA analysis of the "QS" pathway demonstrated that the key genes of the QS systems were down-regulated. In this pathway, either ExpI/ExpR in Erwinia, Serratia or EsaI/EsaR in Pantoea stewartii correspond to lasI (gene 0750)/expR (gene 0751) in the $H$. alvei genome, respectively. The gene 0750 in $H$. alvei $\mathrm{H} 4$ was matched to the two luxI-type genes in the metabolic pathway map represented by "-Inf", and "-Inf" that the readcount value of the gene was zero; the gene 0751 in $H$. alvei $\mathrm{H} 4$ was matched to the two R genes indicated by " -2.7818 ", representing multiple down-regulation (Fig. 4). These indicated that after luxIR knockout, the gene controlling the synthesis of AHLs either does not express or is down-regulated, which is in line with the previously observed phenomenon that no AHL was detected in $\triangle l u x I R$.

Most studies devoted to the investigation of the relationship between AHL and QS genes at the transcriptome level have so far focused on several categories. In the first approach, studies have been performed to knock out some functional genes that control the biological phenotype and study the effects of DEGs on the other pathways and biological phenotypes (Khider et al. 2019; Wilf et al. 2013; Mori et al. 2018; Huang et al. 2019). The second approach is to add the corresponding AHL to the strain that has related knocked out genes (Puri et al. 2017) or the strain (Majerczyk et al. 2014) which does not produce AHL, and monitor the changes in the transcriptional regulation of DEGs before and after the addition of AHL. The third approach is to study the strain at different growth stages (or different cell densities) and this idea is widespread in most transcriptome sequencing. Our approach mainly combined genomic with transcriptome data. We focused on QS-related genes and QS pathways and explained the phenomena we observed in TLC and LC/MS at the molecular level. We have learned from the draft genome map that there could only be one QS system in $H$. alvei $\mathrm{H} 4$ and the special overlapping relationship of $\operatorname{luxI} / R$ gene pairs. This overlapping position of the $l u x I / R$ gene in the genome may have different mechanisms for the regulation of AHL. Furthermore, early sequencing efforts have demonstrated that individual genes can overlap or share one or more nucleotides with adjacent genes (Barrell et al. 1976; Sanger et al. 1977), and overlaps have been demonstrated to be potentially important in transcriptional and translational regulators as they might have influenced the evolution of genes (Keese and Gibbs 1992; Krakauer and Plotkin 2002). Therefore, the research in this paper might also provide some ideas for other genetic studies that contain the same special overlapping relationship. On the other hand, based on the results of TLC, LC/MS and the genomic data, we could 
hav: AT03_12360

Down regulated genes

gene 0750 (-Inf)

hav: AT03_12355

Down regulated genes

gene $0751(-2.7818)$

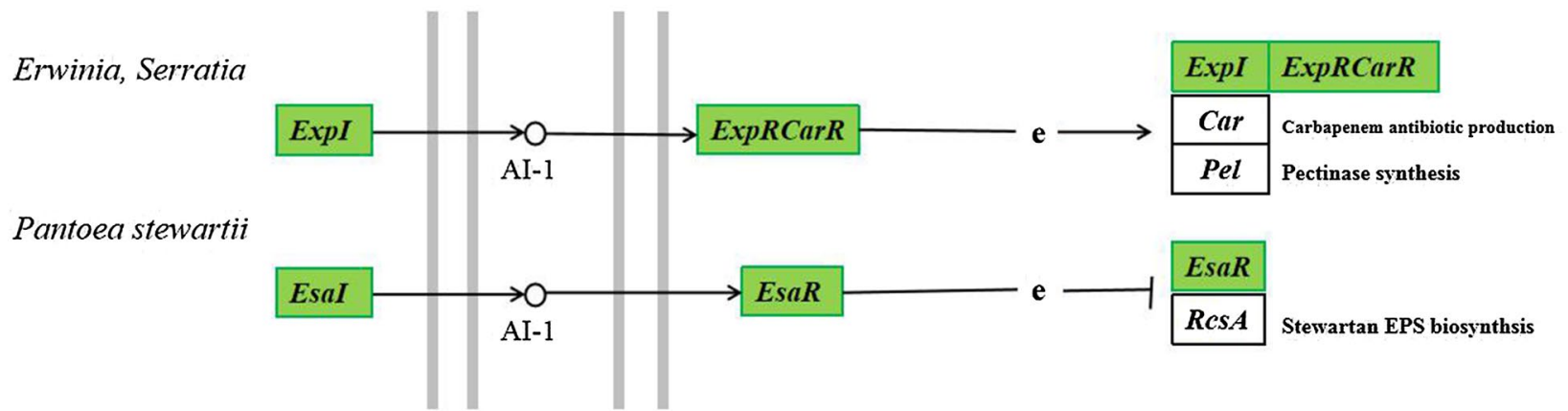

Fig. 4 KEGG "quorum sensing" pathway based on RNA high-throughput sequencing analysis. Proteins appearing in the green boxes are down-regulated at the mRNA level

only obtain one AHL-QS system from the draft genome, and there may be other QS systems in $H$. alvei $\mathrm{H} 4$, as in the case of Pseudomonas chlororaphis subsp. aurantiaca StFRB508 (StFRB508), two sets of AHL-synthase and AHL-receptor genes, phzI/phzR and aurI/aurR that we have identified in the incomplete draft genome of StFRB508, while the complete genome sequence revealed the presence of a third QS gene set, designated as csaI/csaR (Morohoshi et al. 2017). As for H. alvei $\mathrm{H} 4$, the presence of detectable AHL in LC/MS experiments conducted with $\Delta l u x I$ and $\Delta l u x I R$ could increase this possibility. QS signaling is very complex, but we have multiple verifications of its regulatory mechanism at the phenomenal and molecular levels, and it has broadened our appreciation of $H$. alvei $\mathrm{H} 4 \mathrm{QS}$ as a global regulatory system that affects many cellular functions. Moreover, transcriptome analysis has annotated multiple pathways other than QS, and we could better understand the other functions of $H$. alvei $\mathrm{H} 4$ through these pathways. In short, the specific mechanisms of the secretion of different AHLs and their association with the luxI and luxR genes and the transcriptional changes of differential genes in the different growth stages (or different cell densities) of bacteria and their functional characterization will be subjects of our future research, since more study is needed to determine the role of QS in this significant group of bacteria.

\begin{abstract}
Abbreviations
QS: quorum sensing; AHL: N-acyl-1-homoserine lactone; TLC: thin-layer chromatography; LC/MS: high resolution triple quadrupole liquid chromatography/mass spectrometry; SAM: S-adenosylmethionine; acyl-ACP: acyl carrier protein; C6-HSL: N-hexanoyl-L-homoserine lactone; C4-HSL: N-butyryl-L-homoserine lactone; 3-oxo-C8-HSL: N-(3-oxo-octanoyl)-L-homoserine lactone; SNP: single nucleotide polymorphism; Solo R (orphans): QS-related LuxR AHL sensors/regulators which lack a cognate Luxl AHL synthase, which is unpaired QS LuxR-family proteins.
\end{abstract}

\section{Acknowledgements}

This study was supported financially by "The National Natural Science Foundation of China (No. 31871895)" and "The Liaoning Province's Program for Promoting Liaoning Talents" (No. XLYC1808034).

\section{Authors' contributions}

$\mathrm{HHou}, \mathrm{XL}$ and $\mathrm{GZ}$ contributed to the study conception and design. Material preparation, data collection and analysis were performed by $X L$ and $Y Z$. The first draft of the manuscript was written by XL and all authors commented on previous versions of the manuscript. All authors read and approved the final manuscript.

\section{Funding}

This study was supported financially by "The National Natural Science Foundation of China (No. 31871895)" and "The Liaoning Province's Program for Promoting Liaoning Talents" (No. XLYC1808034).

\section{Availability of data and materials}

The data of this research are inserted in the present article; other data is available if needed. The datasets supporting the conclusions of this article are available in the NCBI database in https://www.ncbi.nlm.nih.gov/nuccore/ SDAR00000000.1/ and GEO database in https://www.ncbi.nlm.nih.gov/geo/ query/acc.cgi?acc=GSE137815.

\section{Ethics approval and consent to participate} Not applicable. 


\section{Consent for publication}

Not applicable.

\section{Competing interests}

The authors declare that they have no competing interests.

\section{Author details}

1 School of Food Science and Technology, Dalian Polytechnic University, No.1, Qinggongyuan, Ganjingzi District, Dalian 116034, China. ${ }^{2}$ Liaoning Key Lab for Aquatic Processing Quality and Safety, No.1, Qinggongyuan, Ganjingzi District, Dalian 116034, China.

Received: 18 November 2019 Accepted: 22 November 2019 Published online: 05 December 2019

\section{References}

Anders S, Huber W (2010) Differential expression analysis for sequence count data. Genome Biol 11:R106. https://doi.org/10.1038/npre.2010.4282.2

Barrell BG, Air GM, Hutchison CA III (1976) Overlapping genes in bacteriophage XX174. Nature 264:3. https://doi.org/10.1038/264034a0

Bruhn JB, Christensen AB, Flodgaard LR, Nielsen KF, Larsen TO, Givskov M, Gram L (2004) Presence of acylated homoserine lactones (AHLs) and $\mathrm{AHL}$-producing bacteria in meat and potential role of $\mathrm{AHL}$ in spoilage of meat. Appl Environ Microbiol 70:4293-4302. https://doi.org/10.1128/ aem.70.7.4293-4302.2004

Camilli A, Bassler BL (2006) Bacterial small-molecule signaling pathways. Science 311:1113-1116. https://doi.org/10.1126/science.1121357

Case RJ, Labbate M, Kjelleberg S (2008) AHL-driven quorum-sensing circuits: their frequency and function among the Proteobacteria. ISME 2:345. https ://doi.org/10.1038/ismej.2008.13

Chen J, Koh CL, Sam CK, Yin WF, Chan KG (2013) Short chain N-acyl homoserine lactone production by soil isolate Burkholderia sp. strain A9. Sensors 13:13217-13227. https://doi.org/10.3390/s131013217

Coutinho BG, Mitter B, Talbi C, Sessitsch A, Bedmar EJ, Halliday N, James EK, Cámara M, Venturi V (2013) Regulon studies and in planta role of the Bral/R quorum-sensing system in the plant-beneficial Burkholderia cluster. Appl Environ Microbiol 79:4421-4432. https://doi.org/10.1128/ aem.00635-13

Cude WN, Buchan A (2013) Acyl-homoserine lactone-based quorum sensing in the Roseobacter clade: complex cell-to-cell communication controls multiple physiologies. Front Microbiol 4:336. https://doi.org/10.3389/ fmicb.2013.00336

Dong SH, Frane ND, Christensen QH, Greenberg EP, Nagarajan R, Nair SK (2017) Molecular basis for the substrate specificity of quorum signal synthases. Proc Natl Acad Sci USA 114:9092-9097. https://doi.org/10.1073/ pnas. 1705400114

Frederix M, Downie AJ (2011) Quorum sensing: regulating the regulators. Adv Microbiol Physiol 58:23-80. https://doi.org/10.1016/B978-0-12-38104 3-4.00002-7

Fuqua C (2006) The QscR quorum-sensing regulon of Pseudomonas aeruginosa: an orphan claims itsidentity. J Bacteriol 188:3169-3171. https://doi, org/10.1128/jb.118.9.3169-3171.2006

Galloway WR, Hodgkinson JT, Bowden S, Welch M, Spring DR (2012) Applications of small molecule activators and inhibitors of quorum sensing in Gram-negative bacteria. Trends Microbiol 20:449-458. https://doi. org/10.1016/j.tim.2012.06.003

Gelencsér Z, Choudhary KS, Coutinho BG, Hudaiberdiev S, Galbáts B, Venturi V, Pongor S (2012a) Classifying the topology of AHL-driven quorum sensing circuits in proteobacterial genomes. Sensors 12:5432-5444. https://doi. org/10.3390/s120505432

Gelencsér Z, Galbáts B, Gonzalez JF, Choudhary KS, Hudaiberdiev S, Venturi V, Pongor S (2012b) Chromosomal arrangement of AHL-driven quorum sensing circuits in Pseudomonas. ISRN Microbiol 2012:1-6. https://doi. org/10.5402/2012/484176

González JF, Vittorio V (2013) A novel widespread interkingdom signaling circuit. Trends Plant Sci 18:167-174. https://doi.org/10.1016/j.tplan ts.2012.09.007

Goryachev AB (2009) Design principles of the bacterial quorum sensing gene networks. Wires Syst Biol Med 1:45-60. https://doi.org/10.1002/wsbm.27
Goryachev AB (2011) Understanding bacterial cell-cell communication with computational modeling. Chem Rev 111:238-250. https://doi. org/10.1021/cr100286z

Guo Y, Liu S, Tang X, Wang C, Niu Z, Feng Y (2017) Insight into c-di-GMP regulation in anammox aggregation in response to alternating feed loadings. Environ Sci Technol 51:9155-9164. https://doi.org/10.1021/acs.est.6b063 96

Hou HM, Zhu YL, Wang JY, Jiang F, Qu WY, Zhang GL, Hao HS (2017) Characteristics of $\mathrm{N}$-acylhomoserine lactones produced by Hafnia alvei $\mathrm{H} 4$ isolated from spoiled instant sea cucumber. Sensors -Basel 17:772. https://doi. org/10.3390/s17040772

Hou HM, Wang YF, Zhang GL, Zhu YL, Xu LQ, Hao HS, Wang Y, Lu MS (2018) Effects of sulfide flavors on AHL-mediated quorum sensing and biofilm formation of Hafnia alvei. J Food Sci 83:2550-2559. https://doi. org/10.1111/1750-3841.14345

Hou HM, Zhu YL, Wang YF, Zhang GL, Hao HS (2019) AHLs regulate biofilm formation and swimming motility of Hafnia alvei H4. Front Microbiol 10:1330. https://doi.org/10.3389/fmicb.2019.01330

Huang XZ, Jia B, Li N, Jia JY, He M, He YC, Qin XJ, Cui Y, Shi CL, Liu YH, Shi XM (2019) Transcriptional sequencing uncovers survival mechanisms of Salmonella enterica serovar Enteritidis in antibacterial egg white. mSphere 4:e00700-18. https://doi.org/10.1128/msphere.00700-18

Kabir AH, Roy AG, Alam MF, Islam R (2010) Detection of quorum sensing signals in gram-negative bacteria by using reporter strain CV026. Notulae Scientia Biologicae 2:72-75. https://doi.org/10.15835/nsb244863

Kaw MK, Blumenthal RM (2010) Translational independence between overlapping genes for a restriction endonuclease and its transcriptional regulator. BMC Mol Biol 11:87. https://doi.org/10.1186/1471-2199-11-87

Keese PK, Gibbs A (1992) Origins of genes: "big bang" or continuous creation? Proc Natl Acad Sci USA 89:9489-9493. https://doi.org/10.1073/ pnas.89.20.9489

Khajanchi BK, Sha J, Kozlova EV, Erova TE, Suarez G, Sierra JC, Horneman AJ, Popov VL, Chopra AK (2009) N-acylhomoserine lactones involved in quorum sensing control the type $\mathrm{VI}$ secretion system, biofilm formation, protease production, and in vivo virulence in a clinical isolate of Aeromonas hydrophila. Microbiology 155:3518-3531. https://doi.org/10.1099/ mic.0.031575-0

Khider M, Hjerde E, Hansen H, Willassen NP (2019) Differential expression profiling of $\triangle$ litR and $\triangle r p o Q$ mutants reveals insight into QS regulation of motility, adhesion and biofilm formation in Aliivibrio salmonicida. BMC Genomics 20:220. https://doi.org/10.1186/s12864-019-5594-4

Kimura N (2014) Metagenomic approaches to understanding phylogenetic diversity in quorum sensing. Virulence 5:433-442. https://doi. org/10.4161/viru.27850

Krakauer DC (2000) Stability and evolution of overlapping genes. Evolution 54:731-739. https://doi.org/10.1554/0014-3820(2000)054\%5b0731:saeoo g\%5d2.3.co;2

Krakauer DC, Plotkin JB (2002) Redundancy, antiredundancy, and the robustness of genomes. Proc Natl Acad Sci USA 99:1405-1409. https://doi. org/10.1073/pnas.032668599

Kumar JS, Umesha S, Prasad KS, Niranjana P (2016) Detection of quorum sensing molecules and biofilm formation in Ralstonia solanacearum. Curr Microbiol 72:297-305. https://doi.org/10.1007/s00284-015-0953-0

Langmead B, Salzberg SL (2012) Fast gapped-read alignment with Bowtie 2. Nat Methods 9:357-359. https://doi.org/10.1038/nmeth.1923

Lequette Y, Lee JH, Ledgham F, Lazdunski A, Greenberg EP (2006) A distinct QscR regulon in the Pseudomonas aeruginosa quorum-sensing circuit. J Bacteriol 188:3365-3370. https://doi.org/10.1128/jb.188.9.3365-3370.2006

Love MI, Huber W, Anders S (2014) Moderated estimation of fold change and dispersion for RNA-seq data with DESeq2. Genome Biol 15:550. https:// doi.org/10.1186/s13059-014-0550-8

Majerczyk C, Brittnacher M, Jacobs M, Armour CD, Radey M, Schneider E, Phattarasokul S, Bunt R, Greenberg EP (2014) Global analysis of the Burkholderia thailandensis quorum sensing-controlled regulon. J Bacteriol 196:1412-1424. https://doi.org/10.1128/jb.01405-13

McClean KH, Winson MK, Fish L, Taylor A, Chhabra SR, Camara M, Daykin M, Lamb JH, Swift S, Bycroft BW, Williams P, Stewart GS (1997) Quorum sensing and Chromobacterium violaceum: exploitation of violacein production and inhibition for the detection of $\mathrm{N}$-acylhomoserine lactones. Microbiology 143:3703-3711. https://doi.org/10.1099/00221287-143-12-3703 
Miller MB, Bassler BL (2000) Quorum sensing in bacteria. Annu Rev of Microbiol 55:165-199. https://doi.org/10.1146/annurev.micro.55.1.165

Mori Y, Ishikawa S, Ohnishi H, Shimatani M, Morikawa Y, Hayashi K, Ohnishi K, Kiba A, Kai K, Hikichi Y (2018) Involvement of ralfuranones in the quorum sensing signalling pathway and virulence of Ralstonia solanacearum strain OE1-1. Mol Plant Pathol 19:454-463. https://doi.org/10.1111/ mpp.12537

Morohoshi T, Yamaguchi T, Xie X, Wang WZ, Takeuchi K, Someya N (2017) Complete genome sequence of Pseudomonas chlororaphis subsp. aurantiaca reveals a triplicate quorum-sensing mechanism for regulation of phenazine production. Microbes Environ 32:47-53. https://doi.org/10.1264/ jsme2.me16162

Nagalakshmi U, Waern K, Snyder M (2010) RNA-Seq: a method for comprehensive transcriptome analysis. Curr Protoc Mol Biol 89:4-11. https://doi. org/10.1002/0471142727.mb0411s89

Okutsu N, Morohoshi T, Xie X, Kato N, Ikeda T (2015) Characterization of $\mathrm{N}$-acylhomoserine lactones produced by bacteria isolated from industrial cooling water systems. Sensors 16:44. https://doi.org/10.3390/s16010044

Parsek MR, Val DL, Hanzelka BL, Cronan JE, Greenberg EP (1999) Acyl homoserine-lactone quorum-sensing signal generation. Proc Natl Acad Sci USA 96:4360-4365. https://doi.org/10.1073/pnas.96.8.4360

Patzelt D, Wang H, Buchholz I, Rohde M, Gröbe L, Pradella S, Neumann A, Schulz S, Heyber S, Münch K, Jahn D, Tomasch J, Wagner-Döbler I, Münch R (2013) You are what you talk: quorum sensing induces individual morphologies and cell division modes in Dinoroseobacter shibae. ISME J7:2274-2286. https://doi.org/10.1038/ismej.2013.107

Pinto UM, Viana ES, Martins ML, Vanetti MCD (2007) Detection of acylated homoserine lactones in gram-negative proteolytic psychrotrophic bacteria isolated from cooled raw milk. Food Control 18:1322-1327. https://doi. org/10.1016/j.foodcont.2006.09.005

Puri AW, Schaefer AL, Fu Y, Beck DA, Greenberg EP, Lidstrom ME (2017) Quorum sensing in a methane-oxidizing bacterium. J Bacteriol 199:e00773-16. https ://doi.org/10.1128/jb.00773-16

Ravn L, Christensen AB, Molin S, Givskov M, Gram L (2001) Methods for detecting acylated homoserine lactones produced by Gram-negative bacteria and their application in studies of AHL-production kinetics. J Microbiol Methods 44:239-251. https://doi.org/10.1016/s0167-7012(01)00217-2

Sanger F, Air GM, Barrell BG, Brown NL, Coulson AR, Fiddes JC, Hutchison CA III, Slocombe PM, Smith M (1977) Nucleotide sequence of bacteriophage QX174 DNA. Nature 265:687. https://doi.org/10.1038/265687a0

Sorek R, Cossart P (2010) Prokaryotic transcriptomics: a new view on regulation, physiology and pathogenicity. Nat Rev Genet 11:9-16. https://doi. org/10.1038/nrg2695
Subramoni S, Venturi V (2009) LuxR-family'solos': bachelor sensors/regulators of signalling molecules. Microbiology 155:1377-1385. https://doi. org/10.1099/mic.0.026849-0

Swift S, Lynch MJ, Fish L, Kirke DF, Tomás JM, Stewart GS, Williams P (1999) Quorum sensing-dependent regulation and blockade of exoprotease production in Aeromonas hydrophila. Infect Immun 67:5192-5199

Tan JY, Yin WF, Chan KG (2014) Gene clusters of Hafnia alvei strain FB1 important in survival and pathogenesis: a draft genome perspective. Gut Pathog 6:29. https://doi.org/10.1186/1757-4749-6-29

Tsai CS, Winans SC (2010) LuxR-type quorum-sensing regulators that are detached from common scents. Mol Microbiol 77:1072-1082. https://doi. org/10.1111/j.1365-2958.2010.07279.x

Viana ES, Campos MEM, Ponce AR, Mantovani HC, Vanetti MCD (2009) Biofilm formation and acyl homoserine lactone production in Hafnia alvei isolated from raw milk. Biol Res 42:427-436. https://doi.org/10.4067/s0716 -97602009000400004

Vivas J, Padilla D, Real F, Bravo J, Grasso V, Acosta F (2008) Influence of environmental conditions on biofilm formation by Hafnia alvei strains. Vet Microbiol 129:150-155. https://doi.org/10.1016/j.vetmic.2007.11.007

Waters CM, Bassler BL (2005) Quorum sensing: cell-to-cell communication in bacteria. Annu Rev Cell Dev Biol 21:319-346. https://doi.org/10.1146/ annurev.cellbio.21.012704.131001

Weeks JN, Galindo CL, Drake KL, Adams GL, Garner HR, Ficht TA (2010) Brucellamelitensis VjbR and C12-HSL regulons: contributions of the $\mathrm{N}$-dodecanoyl homoserine lactone signaling molecule and LuxR homologue VjbR to gene expression. BMC Microbiol 10:167. https://doi. org/10.1186/1471-2180-10-167

Wiegand S, Dietrich S, Hertel R, Bongaerts J, Evers S, Volland S, Daniel R, Liesegang $H$ (2013) RNA-seq of Bacillus licheniformis: active regulatory RNA features expressed within a productive fermentation. BMC Genomics 14:667. https://doi.org/10.1186/1471-2164-14-667

Wilf NM, Reid AJ, Ramsay JP, Williamson NR, Croucher NJ, Gatto L, Goulding D, Barquist L, Dougan G, Salmond G, Lilley K, Hester S, Kingsley RA (2013) RNA-seq reveals the RNA binding proteins, Hfq and RsmA, play various roles in virulence, antibiotic production and genomic flux in Serratia sp. ATCC 39006. BMC Genomics 14:822. https://doi. org/10.1186/1471-2164-14-822

\section{Publisher's Note}

Springer Nature remains neutral with regard to jurisdictional claims in published maps and institutional affiliations.

\section{Submit your manuscript to a SpringerOpen ${ }^{\circ}$ journal and benefit from:}

- Convenient online submission

- Rigorous peer review

- Open access: articles freely available online

- High visibility within the field

- Retaining the copyright to your article

Submit your next manuscript at $\boldsymbol{\Delta}$ springeropen.com 